\title{
Differences in Correlation Values in Sex Determination based on Ridge Density of Hypothenar, External Ear Anthropometric and Canine Index
}

\author{
Raja Al Fath Widya Iswara \\ Department of Forensic and Medicolegal, Halu Oleo University, Indonesia
}

(Corresponding author’s e-mail: rajaalfath@uho.ac.id)

Received: 4 August 2020, Revised: 18 May 2021, Accepted: 18 June 2021

\begin{abstract}
Hypothenar region is an area that is often contacts with surfaces during activities, and the ear is proven to be more consistent than face identification in passive biometrics. While, the teeth are hardest part in the human body which covered inside the oral cavity. These 3 parts of the body have a great role forensic identification especially in determining sex. The aim of this study is to know differences in correlation values in sex determination based on ridge density of hypothenar region of the palm, external ear anthropometric and canine index. This was a cross sectional study with observational analytic design, include 500 medical students in Kariadi Hospital Semarang Central Java Indonesia, age 21 - 26 years old, who are included in inclusion criteria, male $(n=250)$, female $(n=250)$. Ridge density is measured by calculating the average number of hypothenar palm ridge on the side of the top, middle and bottom; each area is $5 \times 5 \mathrm{~mm}^{2}$ in measurement. External ear anthrophometric consists ear length, ear breadth, base auricular, lobe length and lobe width. Canine index is calculated by dividing mesiodistal width and intercanine distance in 4 regions. Spearman correlation test between ridge density of hypothenar region palm prints, external ear anthropometric, mandibular canine index and sex shows significant correlation with $p$-value $=0.000$. There is no significant difference between maxillary canine index and sex (right maxillary $p$-value $=0.112$ and left maxillary $p$-value $=0.082$ ). There are differences in correlation values in sex determination based on ridge density of hypothenar region palm prints, external ear anthropometric and mandibular canine index. Ridge density of hypothenar region palm prints and ear length are show strong correlation in sex determination.
\end{abstract}

Keywords: Palm prints, Hypothenar ridge, External ear, Canine index, Sex

\section{Introduction}

Forensic identification plays a very important role in both criminal cases involving forensic and medicolegal fields, as well as in cases such as natural disasters and accidents. Along with the rapid development of science and technology, forensic experts are always looking for and developing new techniques to support the identification process $[1,2]$.

Hypothenar is an area that is often contact with the surface of the object during the activity so it can be used in identification [3-5]. Ear proved more consistent than the face in passive biometrics for the purposes of identification [6-8]. Teeth are the hardest part of the human body and is protected in the oral cavity $[9,10]$. Teeth help forensic investigations to estimate age, determine sex and race of a person even when decomposed or burned [11,12].

Several studies support that ridge of hypothenar, external ear anthropometry and canine index play a role in forensic identification especially in determining sex. The aim of this study is to investigate the differences in correlation values in sex determination based on ridge density of hypothenar region of the palm, external ear anthropometric and canine index.

\section{Materials and methods}

This was a cross sectional study with observational analytic design include 500 subjects of medical students at Kariadi Hospital Semarang Central Java Indonesia, with inclusion criteria 21 - 26 years old, mongoloid race, male $(n=250)$ and female $(n=250)$. The exclusion criteria are having defects or 
congenital anomaly which influence palm print, have wound or scarring on the palms, previous history of craniofacial trauma, ear disease, congenital anomalies or previous surgery to the ear, abnormal teeth alignment, missing anterior teeth, crowded or excessive spacing in the anterior teeth, abnormal over jet and overbite, caries teeth, bad/poor oral hygiene, canine teeth with attrition, subjects with orthodontic treatment, any trauma to canine teeth and reject as research subjects $[3,6,9]$.

Ridge density is measured by calculating the average number of palm ridge on the upper, middle and lower hypothenar sections within each area of $5 \times 5 \mathrm{~mm}^{2}$, as shown in the Figure 1. External ear anthropometry as shown in the Figure 2, by measuring the ear length (EL) is the highest point of free margin on the auricle (superaurale) to the lowest point of the free margin of the lobule (subaurale), the ear breadth (EB) is the anterior most point of the auricle (right in front of the helix structure) to the most posterior point free margin of the helix (postaurale), the base of auricle (BA) is the most anterior point of the auricle (preaurale) to the lowest point of pinna attachment, the lobe length (LL) is the deepest indentation of the tragus to the subaurale and the lobe breadth (LB) is the lowest point of pinna attachment to the most posterior point of the lobule. Canine index by calculating the ratio of width mesiodistal divided the distance between canines in the 4 regions of the right maxillary, left maxillary, right mandibula and left mandibular, as shown in the Figure 3.

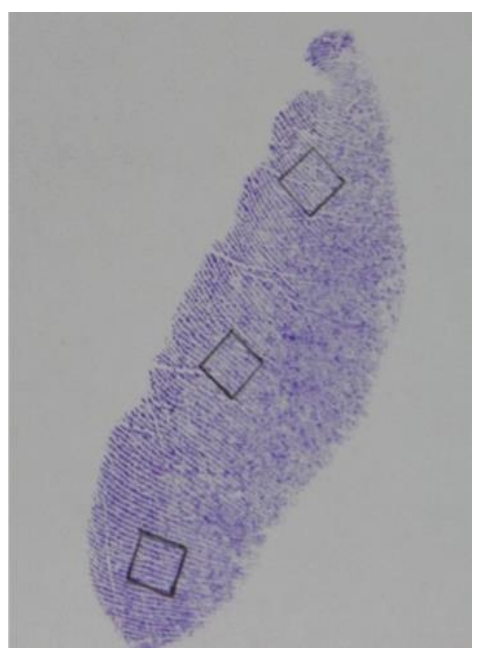

Figure 1 Fingerprinting of hypothenar.

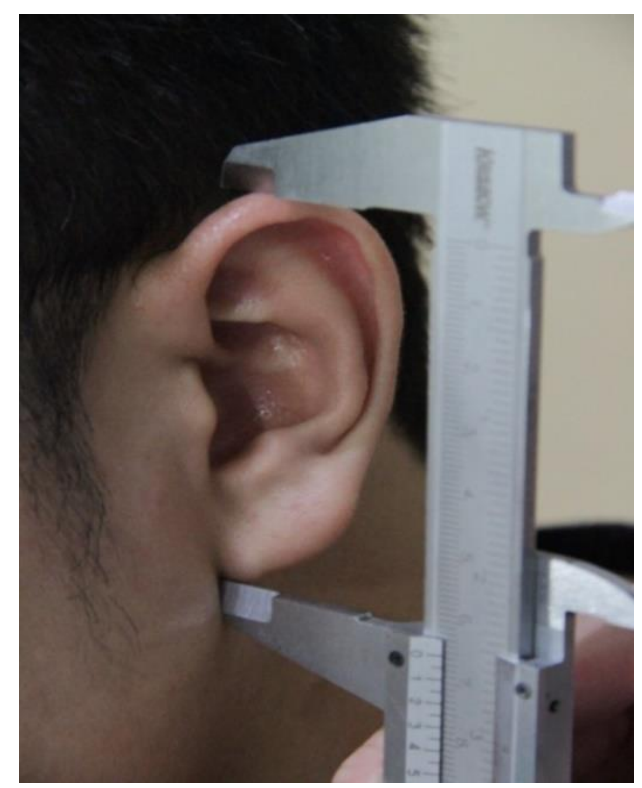

Figure 2 Ear measurements using calipers. 


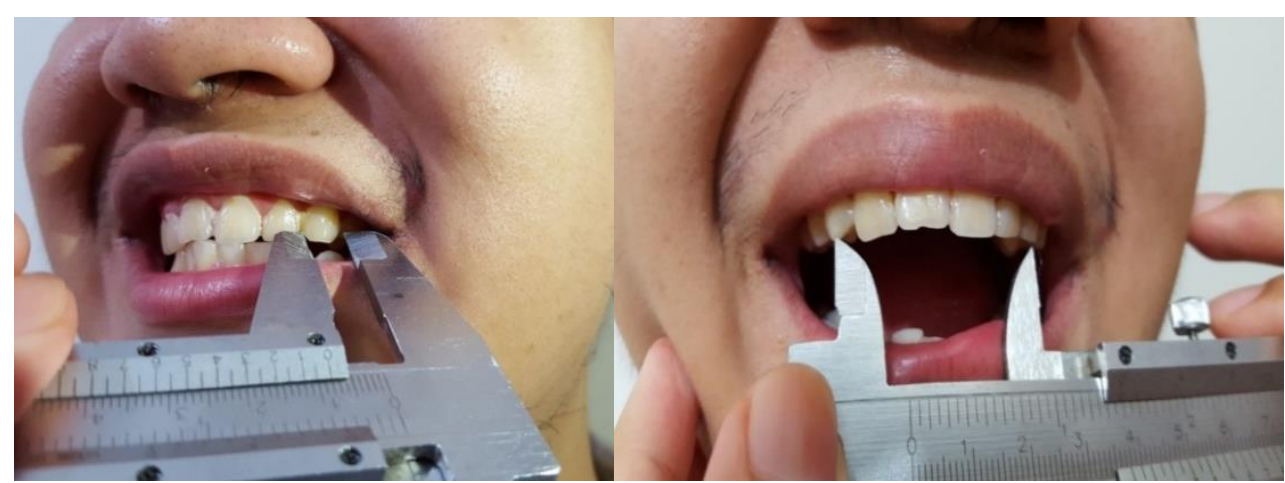

Figure 3 Measurement of mesiodistal width of the left maxillary canine and maxillary intercanine distance.

Characteristics of data are presented in descriptive form with mean and standard intersections for data with normal or median distribution and range for abnormal data distribution. Test normality with Kolmogorov Smirnov followed by Spearman correlation test. Data were analyzed using SPSS 22.

\section{Results and discussion}

In the present study 500 subjects were enrolled, consisting of $250(50 \%)$ male and $250(50 \%)$ females. Table 1 lists the data distribution of ridge density of hypothenar region palm prints, external ear anthropometry and canine index.

Based on the normality test with Kolmogorov-Smirnov seen that most of the data has a value of $p<0.05$. In other words, abnormal data distribution then performed data transformation. Then Spearman correlation test showed significant correlation between ridge density of hypothenar region palm prints, external ear anthropometry, mandibular canine index $(p<0.05)$ and no significant difference between maxillary canine index and sex $(p>0.05)$, as shown in the Tables $2-4$.

Table 1 Data distribution of ridge density of hypothenar region palm prints, external ear anthropometry and canine index.

\begin{tabular}{ccccccc}
\hline Variable & Sex & $\begin{array}{c}\text { Min } \\
(\mathbf{c m})\end{array}$ & $\begin{array}{c}\text { Max } \\
(\mathbf{c m})\end{array}$ & $\begin{array}{c}\text { Mean } \\
(\mathbf{c m})\end{array}$ & $\begin{array}{c}\text { Median } \\
(\mathbf{c m})\end{array}$ & $\begin{array}{c}\text { Std } \\
\text { Dev }\end{array}$ \\
\hline \multirow{2}{*}{ Right hypothenar ridge } & Male & 7 & 13 & 9.816 & 10 & 1.157 \\
\hline \multirow{2}{*}{ Left hypothenar ridge } & Female & 8 & 16 & 11.724 & 12 & 1.292 \\
\cline { 2 - 6 } & Male & 7 & 13 & 10.064 & 10 & 1.177 \\
\cline { 2 - 6 } Right ear length & Female & 8 & 16 & 11.768 & 12 & 1.252 \\
\hline \multirow{2}{*}{ Left ear length } & Male & 6.00 & 8.30 & 7.137 & 7.10 & 0.370 \\
\cline { 2 - 6 } & Female & 5.20 & 7.30 & 6.384 & 6.30 & 0.391 \\
\hline \multirow{2}{*}{ Right ear breadth } & Male & 5.50 & 8.50 & 7.059 & 7.00 & 0.445 \\
\cline { 2 - 6 } & Female & 5.10 & 7.30 & 6.384 & 6.38 & 0.396 \\
\cline { 2 - 6 } & Male & 3.00 & 4.50 & 3.586 & 3.50 & 0.308 \\
\hline \multirow{2}{*}{ Left ear breadth } & Female & 2.60 & 4.00 & 3.188 & 3.20 & 0.259 \\
\cline { 2 - 6 } Rigth base of auricle & Male & 2.70 & 4.30 & 3.474 & 3.50 & 0.305 \\
\cline { 2 - 6 } & Female & 2.20 & 3.90 & 3.107 & 3.00 & 0.276 \\
\hline \multirow{2}{*}{ Left base of auricle } & Male & 4.20 & 7.00 & 5.417 & 5.50 & 0.467 \\
\hline Right lobe length & Female & 3.37 & 6.00 & 4.813 & 4.95 & 0.487 \\
\hline & Male & 4.20 & 6.80 & 5.421 & 5.50 & 0.439 \\
\hline & Female & 3.31 & 6.00 & 4.802 & 5.00 & 0.508 \\
\hline
\end{tabular}




\begin{tabular}{|c|c|c|c|c|c|c|}
\hline Variable & Sex & $\begin{array}{l}\text { Min } \\
(\mathbf{c m})\end{array}$ & $\begin{array}{l}\text { Max } \\
(\mathbf{c m})\end{array}$ & $\begin{array}{c}\text { Mean } \\
(\mathrm{cm})\end{array}$ & $\begin{array}{c}\text { Median } \\
(\mathrm{cm})\end{array}$ & $\begin{array}{l}\text { Std } \\
\text { Dev }\end{array}$ \\
\hline & Female & 1.30 & 2.50 & 1.813 & 1.80 & 0.237 \\
\hline \multirow{2}{*}{ Left lobe length } & Male & 1.00 & 3.00 & 1.960 & 2.00 & 0.293 \\
\hline & Female & 1.20 & 2.50 & 1.798 & 1.80 & 0.231 \\
\hline \multirow{2}{*}{ Right lobe breadth } & Male & 1.09 & 2.80 & 1.999 & 2.00 & 0.277 \\
\hline & Female & 1.20 & 2.70 & 1.816 & 1.80 & 0.252 \\
\hline \multirow{2}{*}{ Left lobe breadth } & Male & 1.20 & 3.00 & 2.015 & 2.00 & 0.267 \\
\hline & Female & 1.30 & 2.70 & 1.817 & 1.80 & 0.231 \\
\hline \multirow{2}{*}{$\begin{array}{l}\text { Right maxillary canine } \\
\text { index }\end{array}$} & Male & 0.138 & 0.264 & 0.2090 & 0.2106 & 0.0228 \\
\hline & Female & 0.125 & 1.994 & 0.2133 & 0.2050 & 0.1152 \\
\hline \multirow{2}{*}{$\begin{array}{l}\text { Left maxillary canine } \\
\text { index }\end{array}$} & Male & 0.128 & 1.578 & 0.2162 & 0.2116 & 0.0898 \\
\hline & Female & 0.151 & 0.270 & 0.2078 & 0.2080 & 0.0210 \\
\hline \multirow{2}{*}{$\begin{array}{l}\text { Right mandibular canine } \\
\text { index }\end{array}$} & Male & 0.156 & 0.324 & 0.2523 & 0.2540 & 0.0262 \\
\hline & Female & 0.164 & 0.300 & 0.2297 & 0.2275 & 0.0234 \\
\hline \multirow{2}{*}{$\begin{array}{l}\text { Left mandibular canine } \\
\text { index }\end{array}$} & Male & 0.156 & 0.324 & 0.2539 & 0.2545 & 0.0247 \\
\hline & Female & 0.164 & 0.300 & 0.2305 & 0.2300 & 0.0224 \\
\hline
\end{tabular}

Table 2 Spearman correlation test of ridge density of hypothenar region palm prints and sex.

\begin{tabular}{cccc}
\hline Variable & \multicolumn{3}{c}{ Sex } \\
& $\mathbf{r}$ & $\boldsymbol{p}$ & $\mathbf{N}$ \\
\hline Right hypothenar ridge & 0.643 & $0.000^{*}$ & 500 \\
Left hypothenar ridge & 0.602 & $0.000^{*}$ & 500 \\
\hline
\end{tabular}

*significant correlation $(p<0.05)$

Table 3 Spearman correlation test of external ear anthropometry and sex.

\begin{tabular}{ccccc}
\hline & Variable & & Sex & N \\
\hline \multirow{2}{*}{ Ear length } & & r & $\boldsymbol{p}$ & 500 \\
& Right & -0.736 & $0.000^{*}$ & 500 \\
Ear breadth & Left & -0.723 & $0.000^{*}$ & 500 \\
& Right & -0.582 & $0.000^{*}$ & 500 \\
Base of auricle & Left & -0.539 & $0.000^{*}$ & 500 \\
& Right & -0.543 & $0.000^{*}$ & 500 \\
Lobe length & Left & -0.561 & $0.000^{*}$ & 500 \\
& Right & -0.287 & $0.000^{*}$ & 500 \\
Lobe breadth & Left & -0.327 & $0.000^{*}$ & 500 \\
& Right & -0.347 & $0.000^{*}$ & 500 \\
\hline
\end{tabular}

*significant correlation $(p<0.05)$

Table 4 Spearman correlation test of canine index and sex.

\begin{tabular}{|c|c|c|c|c|}
\hline \multirow{2}{*}{\multicolumn{2}{|c|}{ Variable }} & \multicolumn{3}{|c|}{ Sex } \\
\hline & & $\mathbf{r}$ & $p$ & $\mathbf{N}$ \\
\hline \multirow{2}{*}{ Maxillary } & Right & -0.071 & 0.112 & 500 \\
\hline & Left & -0.078 & 0.082 & 500 \\
\hline \multirow{2}{*}{ Mandibula } & Right & -0.414 & $0.000 *$ & 500 \\
\hline & Left & -0.448 & $0.000 *$ & 500 \\
\hline
\end{tabular}

*significant correlation $(p<0.05)$ 
This study indicates that there is a correlation between ridge density of the hypothenar region palm prints with sex. Female has greater ridge density than male. In $25 \mathrm{~mm}^{2}$ area, it was found the male have thicker ridges while female have thinner ridges which increases number of count per ridges. Both on the right and left hand is obtained a strong correlation. The results are consistent with research conducted by Chauhan et al in India where the density of the palm ridge female is higher than male [3]. In addition, the results of this study prove previous research conducted by Gungadin [13]; Kralik and Novotny [14]; Keimar et al. [15] all that the palm prints, especially the hypothenar portions, can be used in the determination of the sexes based on the number of ridges themselves. The number of female ridges is higher than male, with an average number of ridges in each different area.

This difference in ridge thickness is thought to be influenced by internal and external factors. In the internal factors of genetic components, especially sex chromosomes that give effect to the thickness of the ridge. Suspected Y chromosome has an effect on the thickness of the ridge is stronger than $\mathrm{X}$ chromosome which resulted in ridge tend to be thicker in male [4,5]. Studies show the possibility that more than 1 gene is involved, so the pattern inheritance cannot be predicted easily. It is thought that the various genes governing the development of various layers of skin, muscle, fat, and blood vessels have a role in the determination of the protrusion pattern [16]. The extent of the valleys on palm prints is thought to be influenced by the surface area of the body, where males a larger area of the body than female as well as the palm area so that male tend to have wider valley and ridge than female $[3,5]$. The wide ridge will provide less density and less number of ridges [4,5].

External factors include trauma, occupation and fetal position and amniotic fluid density. Open wound or burn deep enough to reach the dermis and damage the stratum papilare can leave a permanent scar because of damage to the generating layer [3,4]. Physical activity of pressure can affect the pattern of the ridge, especially repetitive pressure. In addition, certain pressures may produce different patterns of ridges $[4,5]$. The position of the fetus and the density of the amniotic fluid surrounding the fingers as the fetus moves can affect the pattern of ridges due to the different friction of the baby's fingers and palms. This may explain why in monozygotic twins can have the same genetic code but have different ridge patterns.

Large and repetitive pressure will require a larger ridge. Therefore, male with greater workload (emphasis on the palms) have a higher number of ridges than female. In this study a stronger correlation on the right hand, it is influenced by external factors that is the activity where the use of the right hand more often than the left hand so greatly affects the ridge pattern [4,5].

However, unlike research conducted by Kanchan et al. [5] in India which states that there is no statistically significant difference in male and female palmar ridge density because the number of ridges is still often overlaping between males and females. Similarly, Krishan et al. [17] found that the density the palm ridge cannot be used as an effective tool in sex determination. This is because the number of internal and external factors that can affect the density of the palm ridge. Previous research has also stated that men have more ridge than women, as Reddy [18] did in India in 1975 and Platto et al. [19] in America. It is allegedly due to some errors in the method of calculation is not detailed in the specific research calculations $[18,19]$.

An external ear anthropometry found significant differences in ear length, ear breadth, auricula (base of auricle), lobe length and lobes breadth. Strong correlation of ear length with sex, moderate correlation of ear breadth and base of auricle, and weak correlation of lobe length and lobe breadth. This is similar to previous research in India. These findings, including the maximum ear growth rate at a given age by sex, are assumed to be closely related to the genetic origin that differentiates the 2 sexes although not yet clearly described [6-8].

However, in a study conducted by Murgod et al. [8] showed that lobes length and lobe breadth were found to be greater in women than in men. Research by Ferrario et al. [20] showed that all anthropometry of the ear on both sides of the male greater than women. The findings are consistent with the results of this study. A study conducted by Meijerman et al. [21] in the Netherlands is likely to underlie the findings of subsequent studies comparing ear measurements on male and female sex. Where the ear length grows with a rate of about $0.18 \mathrm{~mm} /$ year in male and $0.16 \mathrm{~mm} /$ year in female.

Differences in the anthropometry of the external ear are influenced by both internal and external factors. On internal factors, genetic factors and congenital abnormalities will cause anatomical abnormalities of the ear of the ear which will affect anthropometry of the ear [20,21]. While external factors, trauma is a major factor affecting the anatomy of the ear itself. Where the lesions of the ear, for example, loss of 1 part of the ear (helix, antihelix, concha, tragus, antitragus, scapha, lobule or triangular fossa) may affect anthropometry of the ear [20]. In this study the most influential major factors are internal factors (genetic factors), in men's ear growth is faster than women [21]. 
This research is different from the research conducted by Barut and Aktunc who said that there is no significant difference between right ear antropometry between men and women, whereas on the left ear anthropometry in men is greater than women. This is thought to be due to the effect of errors in measurements or external factors on the ear. Broadly speaking anthropometry of the ear is influenced by genetic, race, individual constitution, environment and age [22].

The right and left mandibular canine indexes showed significant moderate correlation whereas in the maxilla there was no significant difference from the right and left caninus index between the male and female groups. Sassi et al. [10] research conducted in Uruguay showed similar results with the results of the current author. The results obtained regarding mesio-distal width and mandibular inter-canine distance showed statistically significant differences for the discrimination of female and male sexes. The sample is the age group of adults to the age of 21 - 60 years old [10,11].

Some internal factors have a great influence on tooth morphology. Genetic factors have the greatest influence in dental morphology itself such as dental malformations, tooth size. Gene expression in men is greater than female. It is assumed that the effect of Y chromosome is not the same on all teeth which strongly affect the thickness of dentine, while the $X$ chromosome affects enamel thickness [23]. In addition, hormonal factors also greatly affect both morphology and eruption of the tooth itself. Disease factors such as Down syndrome, Cleidocranial dysostosis, hypothyroidism, hypopituarism, craniofacial synostosis and hemifacial atrophy [24].

External factors that affect dental morphology are trauma to the tooth itself, both intentional and unintentional and the dietary habits of the person itself [25]. Mandibular canines are usually smaller and shorter than the maxillary canines [25]. In this study, influential is the internal factors that play a role in the development of the tooth itself while the external factors have no effect because it becomes the inclusion criteria research.

In a study conducted by Nahidh [29], sexual dimorphism was found in measuring the mesio-distal width of the maxillary first incisor and maxillary caninus by measuring the width between the right and left canines. Because the mesio-distal size of a woman's teeth is smaller than that of men, the size of the female jaw arch is smaller than that of men [26,27]. In fact, the size and shape of the male and female teeth are almost identical, making it difficult to carry out gender determinations. In teeth, the most used for sexual dimorphism is the mandibular caninus. Anderson states that if the mesiodistal diameter is less than $6.7 \mathrm{~mm}$ is female, whereas if more than $7 \mathrm{~mm}$ is male (74 \% in case evaluation). The maxillary caninus also has differences in men and women, ie at root lengths, on average in men as much as $3 \mathrm{~mm}$ longer than women. These measurements are only valid if done on perfect teeth, which do not experience abrasion [28,29].

In general, the determination of sex based on the index caninus has an accuracy value of $75 \%$, in accordance with research in North India (75\%), South India (82.2 - 85.9\%), Punjabi-Pakistan population (76\%), while research conducted by Muller et al. [30] in the French population showed a low predictive value $(59.57 \%)$. From Nair et al. [31] study in South India it was found that the left mandibular canine index showed $7.7 \%$ dysmorphism while in the mandibular mandibular index jaw of $6.2 \%$.

\section{Conclusions}

There are differences in correlation values in sex determination based on ridge density of hypothenar region palm prints, external ear anthropometric and mandibular canine index. Ridge density of hypothenar region palm prints and ear length are show strong correlation in sex determination.

\section{Acknowledgements}

We would like thank to the God, the almighty, creator of universe for his great love towards us during this research paper. Secondly all our thanks go straight to all those from far and near, who actively contributed to the writing of this paper. 


\section{References}

[1] R Bardale. Principles of forensic medicine \& toxicology. Jaypee Brothers Medical Publishers, New Delhi, India, 2011, p. 39-40.

[2] P Saukko and B Knight. Knight's forensic pathology. $4^{\text {th }}$ ed. CRC Press, London, 2016, p. 95.

[3] A Chauhan, S Jyoti and KKP Singh. An evaluation sexing from the ridge density of latent palm prints north indian population. Res. J. Recent Sci. 2015; 4, 73-5.

[4] A Chauhan. Determination of sex from the latent palm prints present on documents. J. Forensic Res. $2015 ; 6,1000300$.

[5] T Kanchan, K Krishan, KR Aparna and S Shyamsundar. Is there a sex difference in palm print ridge density? Med. Sci. Law 2013; 53, 33-9.

[6] V Murgod, P Angadi, S Hallikerimath and A Kale. Anthropometric study of the external ear and its applicability in sex identification: Assessed in Indian Sample. Aust. J. Forensic Sci. 2013; 45, 43144.

[7] V Kapil, J Bhawana and K Vikas. Morphological variation of ear for individual identification in forensic cases: A study of an indian population. Res. J. Forensic Sci. 2014; 2, 1-8.

[8] R Fooprateepsiri and W Kurutach. Ear based personal identification approach forensic science tasks. Chiang Mai J. Sci. 2011; 38, 166-75.

[9] SM Bakkannava, S Manjunath, VC Nayak and GP Kumar. Canine index - a tool for sex determination. Egypt. J. Forensic Sci. 2015; 5, 157-61.

[10] C Sassi, A Picapedra, LNC Lima, LF Júnior, E Daruge and ED Júnior. Sex determination in uruguayans by odontometric analysis. Braz. J. Oral Sci. 2012; 11, 381-6.

[11] HMA Ahmed. Gender identification using mandibular canines (iraqi study). J. Bagh. Coll. Dent. $2014 ; 26,150-3$.

[12] G Maneel, RG Bai, T Ram, PM Puri and KR Ghodke. An Odontologist's key to sex determination study analysis of mandibular canine teeth in south Indian population. J. Orofac. Res. 2013; 3, 157 60.

[13] S Gungadin. Sex determination from fingerprint ridge density. Internet J. Med. Update 2007; 2, 1-4.

[14] M Kralik and V Novotny. Epidermal ridge breadth: An indicator of age and sex in paleodermatoglyphics. Variability Evol. 2003; 11, 5-30.

[15] L Keimar, S Agarwal, R Garg, A Pratap and VK Mishra. Gender determination using fingerprints in the region of uttarakhand. J. Indian Acad. Forensic Med. 2013; 35, 308-10.

[16] PJ Lakshmi and R Thenmozhi. A short reviews on dermatoglyphics. J. Pharm. Sci. Res. 2014; 6, 200-2.

[17] K Krishan, T Kanchan, R Sharma and A Pathania. Variability of palmprint ridge density in a north indian population and its use in inference of sex in forensic examination. J. Comp. Hum. Biol. 2014; 65, 476-88.

[18] GG Reddy. Finger dermatoglyphic of the bagathas of araku valley. Am. J. Phys. Anthropol. 1975; 42, 225-8.

[19] CC Platto, JJ Cereglino and FS Steinberg. The dermatoglyphics of america caucasion. Am. J. Phys. Antrhopol. 1975; 42, 192-210.

[20] VF Ferrario C Sforza, V Ciusa, G Serrao and GM Tartaglia. Morphometry of the normal human ear: A cross-sectional study from adolescence to mid-adulthood. J. Craniofac. Genet. Dev. Biol. 1999; 19, 226-33.

[21] L Meijerman, CVD Lugt and GJR Maat. Cross sectional anthropometry study of the external ear. $J$ Forensic Sci. 2007; 52, 286-93.

[22] C Barut and E Aktunc. Anthropometric measurements of the external ear in a group of Turkish primary school students. Aesthetic Plast. Surg. 2006; 30, 255-9.

[23] SM Garn, AB Lewis, DR Swindler and RS Kerewsky. Genetic control of sexual dimorphism in tooth size. J. Dent. Res. 1967; 46, 963-72.

[24] GR Scott. Dental morphology. In: MA Katzenberg and SR Saunders (Eds.). Biological anthropology of the human skleton. $2^{\text {nd }}$ ed. John Wiley \& Sons, New Jersey, 2008, p. 265-98.

[25] CM Bowers. Forensic dental evidence and investigators handbook. Academic Press, Massachusetts, United States, 2004.

[26] K Boaz and C Gupta. Dimorphism in human maxillary and mandibular canine in establishment of gender. J. Forencis Dent. Sci. 2009; 1, 42-4.

[27] S Ruengdit, S Riengrojpitak, M Tiensuwan and P Santiwong. Sex determination from teeth size in thais, thailand. In: Proceedings of the $6^{\text {th }}$ CIFS Academic Day 2011, Nonthaburi, Thailand. 2011. 
[28] M Grover, RG Bai, T Ram, PM Puri and KR Ghodke. An Odontologist's key to sex determination study analysis of mandibular canine teeth in south indian population. J. Orofac. Res. 2013; 3, 15760.

[29] M Nahidh. The value of maxillary central incisors and canines in gender determination as an aid in forensic dentistry. Iraqi Dent. J. 2014; 36, 9-11.

[30] M Muller, L Lupi-Pegurier, G Quatrehomme, M Bolla. Odontometrical method useful in determining gender and dental alignment. Forensic Sci. Int. 2001; 121, 194-7.

[31] P Nair, BB Rao and RG Annigeri. A study of tooth size, symmetry and sexual dimorphism. $J$. Forensic Med. Toxicol. 1999; 16, 10-3. 